\title{
Thunderbolt hunt. Educational Program for Students from 5 to 9 Years Old in the Archaeological Museum of Ioannina
}

\author{
Athina C. Kornelaki ${ }^{1, *} \&$ Katerina Plakitsi ${ }^{1}$ \\ ${ }^{1}$ Department of Early Childhood Education, School of Education, University of Ioannina, Greece \\ *Correspondence: Department of Early Childhood Education, School of Education, University of Ioannina, Greece. \\ Tel: 30-698-415-1653. E-mail: athinako91@yahoo.com
}

Received: June 20, 2018

Accepted: July 18, $2018 \quad$ Online Published: August 6, 2018

doi:10.5430/wje.v8n4p87

URL: https://doi.org/10.5430/wje.v8n4p87

\begin{abstract}
The present study aims to improve the quality and the effectiveness of Science Education in early grades along with the goals of UNESCO's emerging agenda for sustainable development and the $4^{\text {th }}$ goal about quality in education. It examines the interaction between formal and non-formal education in designing and organizing complete educational programs directly connected with science education curriculum and utilizing innovative tools targeting to an attractive and rich context for science education. According to the second Science Centre World Summit (SCWS, 2017), museums promote scientific knowledge which is considered a pure cultural component and as such it is studied under the prism of cultural historical activity theory. Activity Theory is used in this research as a theoretical framework for the design and analysis of educational activities, with an emphasis on active and interactive learning processes. It is a predominantly socio-cultural theory offering a broad scope of design and implementation for linking science with culture and society. The educational program developed, "Thunderbolt hunt", is different from the usual educational programs offered because, although it cultivates scientific method skills, it is implemented in the Archaeological museum of Ioannina which constitutes a non-formal learning environment of general interest. The process of designing such programs is based on a number of principles and on numerous fields: the socio-cultural theory of activity, the science education and the museum education. The museum thus becomes a facilitator of scientific knowledge while at the same time functions as a dynamic meeting place for students with their social, cultural and historical environment. The preliminary results of the study are presented in this paper.
\end{abstract}

Keywords: activity theory, educational program, archaeological museum, scientific method skills

\section{Introduction}

This paper presents the preliminary results of a research study that focuses on the connection of Science Education in early grades with the Cultural Historical Activity Theory (CHAT) within non-formal settings. @fise (Activity Theory in Formal, Informal Science Education) research group has been working intensively for the last 10 years on the transfer of CHAT in Science Education in early grades mostly in formal settings (Kolokouri \& Plakitsi, 2016; Kolokouri, Theodoraki \& Plakitsi, 2012; Nanni \& Plakitsi, 2013; Stamoulis \& Plakitsi, 2014; Kornelaki \& Plakitsi, 2018; Stylianou \& Plakitsi, 2015). The present study attempts to expand and widen CHAT's application in non-formal settings.

\subsection{Science Education in Non-Formal Settings}

Science museums and science centers constitute strong social change agents (Plakitsi, 2013) utilizing science as a tool for scientifically literate societies and participatory citizenship. Tokyo Protocol (November 2017), emerged from the second Science Centre World Summit (SCWS2017), recognizes the Sustainable Development Goals (SDGs) endorsed by the United Nations (2015) as principal priority in global prosperity. In this sense, Science, Technology, Engineering and Mathematics (STEM) are seen as significant factors for achieving SDGs and platforms of public engagement in global sustainability as they compound fields universally relevant across borders and cultures. Museums are pure cultural institutions and as such they can obtain a central part in achieving the goals of our planet in an ever-changing society. Free access to all people constitutes a universal human right promoting engagement in diverse audiences and gender equality. 
In museums people are engaged with scientific knowledge, they build links between science and their everyday life and discover the extent to which life is affected by science, they behold real, authentic objects, become acquainted with their culture, cultivate scientific inquiry methods and work together within the educational programs offered and above all they adopt positive stance towards science and museum (Plakitsi, 2008; Plakitsi, 2013). Tokyo Protocol binds science centers and museums to strive achieving "a positive global impact and making people aware of the opportunities that science and technology hold for the sustainable advancement of humankind" (SCWS2017).

\subsection{Rationale and Purpose}

To benefit from the above requires people to have access to a science center or museum close to their place of residence. In Greece the number of those institutions is very limited, and they are confined to big urban areas. The above automatically excludes the regions of convergence. With the present study we propose filling the gap with the development and implementation of complete scientific educational programs, directly connected with the science education curriculum and the deployment of innovative tools. The latter is proposed with the use of a framework of design and implementation which adopted the basic principles of CHAT theory. This framework is further described below.

The rationale of the study was based on the consensus view about the integration of science education in early grades as a result of children's curiosity as well as their innate need to discover and explore the world around them (Tu, 2006; Fleer, 2009; Greek Ministry of Education, 2011; Roth, Goulard \& Plakitsi, 2013) and eventually, the establishment of foundation and positive stance about science (Roth, 2011).

The designed educational program "Thunderbolt hunt" was implemented in the Archaeological Museum of Ioannina. It is noteworthy that Ioannina belongs to one of the eight regions of convergence in Greece. The study proposes informal settings such as museums of general interest (archaeological, historical, folklore, art etc.) to offer their audience educational programs which are inspired by concepts of science education, cultivate scientific method skills, they are derived from museum artifacts and thus, they promote and communicate culture. This is the added value of the current study and the innovation it introduces.

As mentioned above, the research was based on the ideas and principles of CHAT theory. In this frame the study attempts to answer the questions:

- How did the learning community in the case of the museum mediate science education and vice versa?

- Which scientific method skills were practiced during the educational program "Thunderbolt hunt"?

- Which interactions were identified within the activity system during the implementation of the educational program "Thunderbolt hunt"?

\subsection{CHAT Framework}

CHAT is used in the present study as the theoretical framework for the design and analysis of educational programs focusing on active and interactive learning processes. It constitutes a pure socio-cultural theory offering a broad field of design and implementation to connect science with culture and society. The basic unit of analysis is the activity itself in which collaboration and language possess central roles as tools that help shape the individual's identity (Leontiev, 2009, Kaptelin \& Nardi, 2006). The unit of analysis integrates the dynamic interaction of the social, cultural and historical aspects of development. Thus, museums function as a dynamic meeting place for students with their social, cultural and historical environment (Plakitsi, 2008). Towards that, development is seen as a constant, dynamic process of being, which is situated in a cultural, historical context (Holzman, 2010; John- Steiner, Connery, \& Marjanovic-Shane, 2010; Wertsch, 1998; Cole, 1988). Thereby, all the structural components of the activity system (Engestrom, 1999) are in constant interdependencies and interactions.

The constant interaction of the activity's structural components causes friction. Friction therefore, can cause contradictions, which are manifested as "disturbances within the components, between each other, between different activities or between different developmental phases of a single activity" (Engestrom, 1987; Kuuti, 1996). The contradictions in CHAT have a fundamental role as they are considered the spark for the development of human activity and exist in every system of collective activity. Only when the contradictions are identified, then it is possible to "reconstruct the system with its clear diversity and wealth" (Foot \& Groleau, 2011).

Museums promote scientific knowledge, which is considered a cultural component (Koliopoulos, 2005). Moreover, museums deal with socio-scientific issues (Beetlestone, Johnson, Quin \& White, 1998; Wellington, 1998) and therefore, they can only be studied in the light of the CHAT framework. Accordingly, the study was based on the basic ideas and principles of CHAT framework. Learning is a collective process and man learns by doing and 
communicating with and through his actions (Foot, 2014; Stetsenko, 2017). Hence, learning community plays an important role under a CHAT perspective in constructing and interpreting meanings (Vygotsky, 1978). Tools, material and/or immaterial, mediate learning and human actions. Mediation is the central idea in Vygotsky's theory (Basharina, 2007) about child's development. The principle of mediation states that an individual's learning and development are accomplished through mediation with its culture $($ Cole, 1998) as it does not directly interact with its environment.

CHAT provides a conceptual prism through which we attempt to analyze the interactions between the different components of the activity system while conducting educational programs in the museum, including not only interpersonal, but also cultural and historical aspects (Foot 2014). Engestrom $(1993,1999)$ introduced an activity system (extended triangle of activity theory) the components of which are the: subject, object, tools, rules, community and division of labor. Attempting to represent the activity system of the current research, we would get the model below (Figure 1).

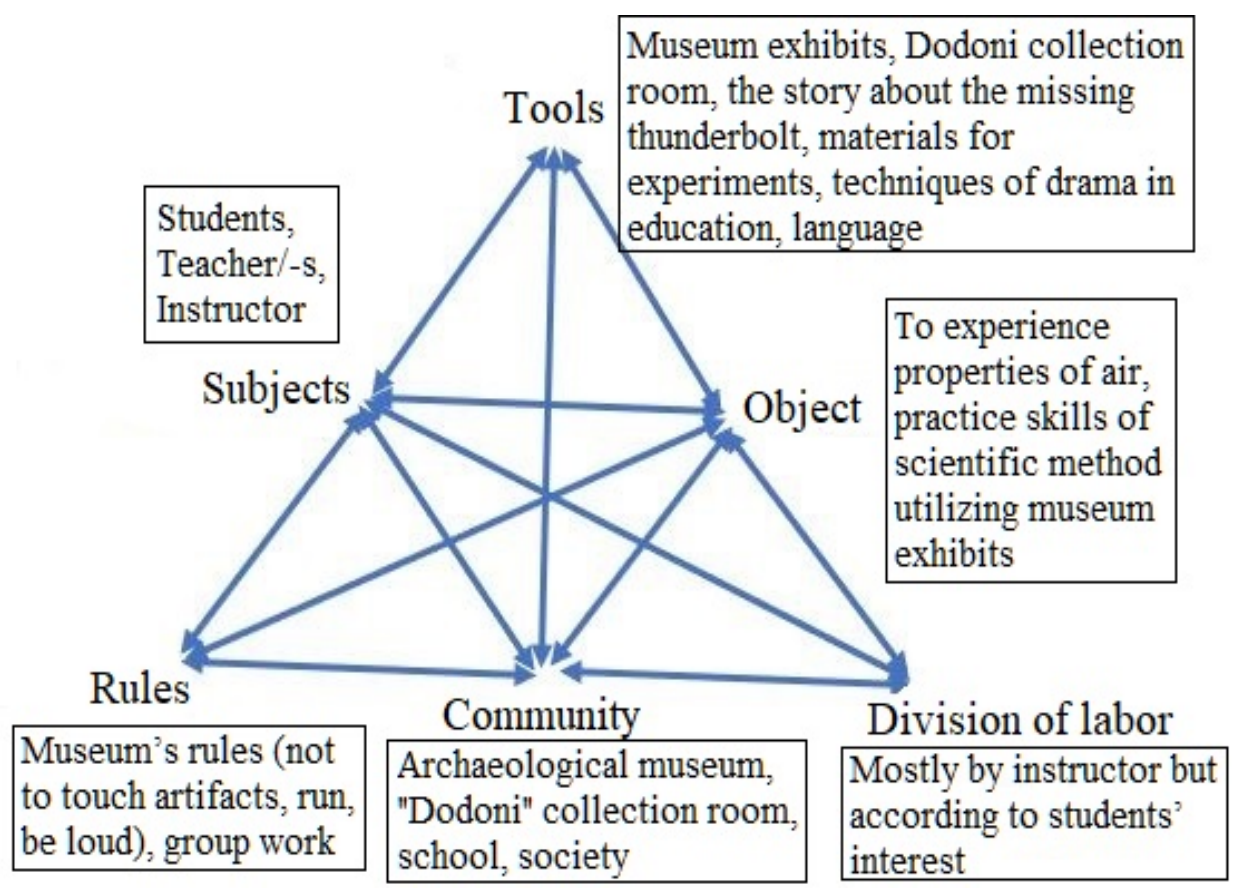

Figure 1. Activity System of the educational program "Thunderbolt hunt"

\section{Method}

\subsection{Type of Research}

The research design was based on the theory of expansive learning (Engestrom, 1987). The present study is part of a broader research which constitutes a system of consecutive expansive learning cycles. The system consists of three expansive learning cycles in total and the present paper refers to the third expansive learning cycle of the system.

Expansive learning is a developmental work research methodology (Virkkunen \& Newnham, 2013) that aims to change and improve the current activity by identifying and resolving contradictions (Engestrom, 2003). It usually signifies the crossing of the boundaries between individual and collective learning, leading to the development of new organizational practices in educational institutions and systems.

The expansive learning cycle is not a universal formula of phases or stages. A typical sequence of actions of an expansive learning cycle is described by Engeström (1999) and is presented in Table 1. 
Table 1. The Phases of an Expansive Learning Cycle (Engeström, 1999)

\begin{tabular}{lll}
\hline \multicolumn{1}{c}{ Phase } & \multicolumn{1}{c}{ Content } \\
\hline 1. Questioning & Need analysis - dispute of aspects of the current activity \\
2. Analyzing the situation & $\begin{array}{l}\text { Analysis of historical and systemic causes of the problems } \\
\text { Creating a new model - Finding a new interpretation of activity's } \\
\text { purpose (object) and a new way of organizing it } \\
\text { 3. Modeling }\end{array}$ & $\begin{array}{l}\text { Testing the new model - Applying in order to examine its dynamics, } \\
\text { potential and limitations }\end{array}$ \\
4. Examining the new model & Applying the new model, enriching and find conceptual extensions \\
5. Implementing the model & Evaluation of the new model and consolidation of results \\
6. Reflecting and evaluating &
\end{tabular}

The third expansive learning cycle includes phases 3, 4, 5 and 6 . In this paper phases 3 and 4 are presented thoroughly whereas phases 1 and 2 are studied in prior expansive learning cycles and researches (Kornelaki \& Plakitsi, 2014; Kornelaki \& Plakitsi, 2017; Kornelaki \& Plakitsi, 2018).

\subsection{Description of Research Design}

Gutwill and Allen (2012) suggest the design of activities that bridge formal with non-formal learning and stray away from conceptual change, which is replaced by the promotion and practice of scientific method skills which provide students with significant advantages towards scientific and technological literacy (Plakitsi, 2008). Critical thinking and scientific method processes constitute very important skills in students' engagement and understanding of scientific knowledge. Students explore, describe objects and phenomena, formulate questions and assumptions, predict, construct interpretations that they experience by experimenting, communicating their ideas, come to conclusions.

The scientific method skills are promoted by both formal and non-formal learning environments (Plakitsi, 2013) and constitute the meeting place of science education and museum education (Plakitsi, 2008). The above triggered the design of the educational program "Thunderbolt hunt" which was designed to be implemented in non-formal settings and embedded principles from both fields. The basic features for design of the educational program are listed below:

1. Definition of the target group (age, level etc.)

2. Connection of the museum exhibits with science education concepts

3. Link to the science education curriculum

4. Collaborative learning

5. Learning by doing

6. Balance between free choice and guidance

7. Instructor's role

8. Teacher's role

\subsubsection{The Educational Program "Thunderbolt hunt"}

The educational program was designed on the occasion of the invitation of the Museums Directorate for participation in the Pan-Hellenic Action entitled "Environment and Culture". The events of the action were related to the four elements of nature, and in 2017 they completed their cycle with the last element, the air, which had a central place in this year's action, "Wind Breaths".

The aim of the program was the students to experiment with air and get to know some of its properties utilizing mythological elements and characters as well as museum exhibits and their history. The specific goals of the program were for students to practice scientific method skills, to understand the existence of the air and that air occupies volume, to use tools in different ways in order to achieve the object.

The duration of the program was 90 minutes and it was consisted of 7 different activities. The activities are presented in Table 2. 
Table 2. The Activities of the Educational Program "Thunderbolt Hunt"

\begin{tabular}{|c|c|c|}
\hline No & Activity & Short description \\
\hline 1 & $\begin{array}{l}\text { Group formation and discussion } \\
\text { about museum exhibits }\end{array}$ & $\begin{array}{l}\text { Students are welcomed in the collection room "Dodoni". They are } \\
\text { taking one card which illustrates an exhibit. The cards form the three } \\
\text { groups. A discussion takes place about the cards and what students } \\
\text { think they represent. }\end{array}$ \\
\hline 2 & $\begin{array}{l}\text { Search for museum exhibits - } \\
\text { The common element }\end{array}$ & $\begin{array}{l}\text { The first task for the groups is to use the tools given (magnifiers, } \\
\text { torches etc.) in order to find the exhibit which is illustrated in the } \\
\text { group's cards and observe it. When all the groups find their exhibit, } \\
\text { they describe it to the rest of the groups and altogether try to figure out } \\
\text { the common element which is the thunderbolt. }\end{array}$ \\
\hline 3 & $\begin{array}{l}\text { How was the thunderbolt lost? } \\
\text { - Narrative }\end{array}$ & $\begin{array}{l}\text { This activity constitutes a narrative about Dodoni's oracle, which is } \\
\text { pictured on the wall, and explains how Zeus lost his thunderbolt when } \\
\text { Aeolus set his winds free from his sack without warning Zeus. Now } \\
\text { Aeolus is accused, threatened for his life and ordered by Zeus to find } \\
\text { thunderbolt. Aeolus turns to students for help. }\end{array}$ \\
\hline 4 & Experiments on air & $\begin{array}{l}\text { The common element of activity } 2 \text { gives students the pass for the next } \\
\text { task, which is the experiments about air and its properties. Students do } \\
\text { the experiments by using the materials given (balloons, straws, syringes, } \\
\text { plastic bottles with or without a hole etc.), test their predictions, } \\
\text { communicate their findings, draw conclusions and generally gather data } \\
\text { in order to help Aeolus by giving him advices on where and how to find } \\
\text { the thunderbolt. }\end{array}$ \\
\hline 5 & Role on the wall & $\begin{array}{l}\text { Students draw or write their advices and give them to Aeolus. He is } \\
\text { pictured on a big paper and students glue their ideas on his head, so he } \\
\text { can think and choose the best idea to find the thunderbolt. }\end{array}$ \\
\hline 6 & Zeus' winged thunderbolt & $\begin{array}{l}\text { While he is fast as the wind, Aeolus shortly and secretly leaves pieces } \\
\text { of the thunderbolt to the instructor and students have to assemble the } \\
\text { pieces of the puzzle to get the Zeus' thunderbolt. }\end{array}$ \\
\hline 7 & Aeolus' sack & $\begin{array}{l}\text { Aeolus surprises students with the last task which aims to decompress. } \\
\text { Before students leave the museum, they are asked to gather Aeolus' } \\
\text { winds and put them back into his sack which is left to the instructor. } \\
\text { When all the winds are in the sack one or more students tie the sack } \\
\text { with a band, so the winds won't escape. }\end{array}$ \\
\hline
\end{tabular}

The educational program includes 4 different kind of activities. There are activities which help practice scientific method skills $(2,4)$, activities of drama in education $(5,7)$, games $(6)$ and finally, activities related to every day-life situation (3). In the following cluster analysis (Figure 2), the grouping of the activities is validated. Cluster analysis dendogram in NVivo groups together items with a higher degree of similarity based on the coding. This is helpful when you are exploring the connections between different items. Therefore, reading the diagram we notice that activities 2 and 4 clearly belong to one big group of activities. They are both related with scientific method skills and they are also connected with the activity 3 which links the museum exhibits with the experiments and that explains its location on the dendogram. In the same way we find activities 5 and 7 close to each other as they are both activities which deploy techniques of drama in education. Activity 6 seems also connected in the dendogram with 5 and 7. In activity 5 students give Aeolus a piece of advice about the lost thunderbolt, in activity 6 he gives students the pieces of the thunderbolt to assemble them and finally, in activity 7 he asks students to gather his winds in his sack. So, the element that links the activities 5,6 and 7 into a broader group is Aeolus. 


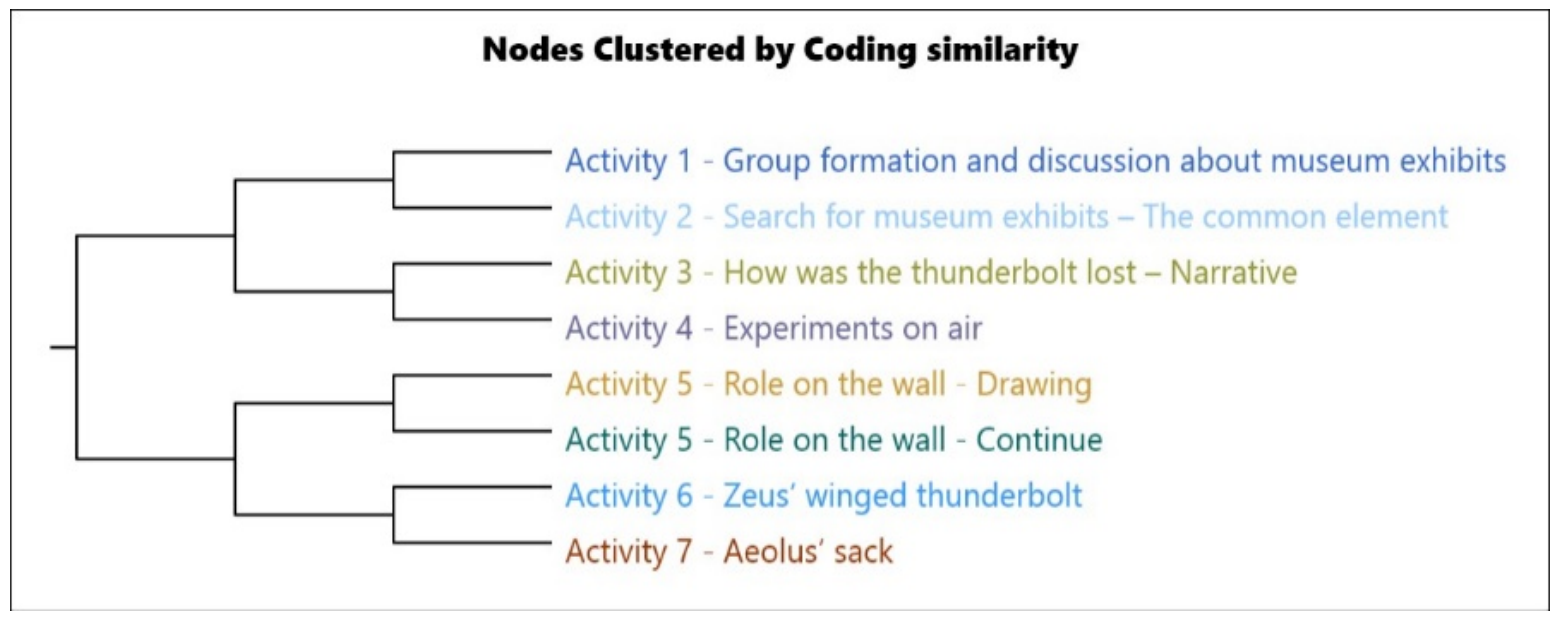

Figure 2. Cluster Analysis Dendrogram of Educational Program's Activities Based on Coding Similarity

\subsection{Data Collection}

The educational program "Thunderbolt hunt" was implemented in Autumn - Winter 2017 in 8 different school classes. The data was collected by video recordings, photographs, students' drawings and field notes and was analyzed with NVivo 9 software by creating a new project. The total sample of the study as well as the collected data are presented in the following tables (Table $3 \&$ Table 4 ).

Table 3. The Sample of the Research

\begin{tabular}{|c|c|c|c|}
\hline $\begin{array}{c}\text { Schools of } \\
\text { Ioannina }\end{array}$ & School grade & $\begin{array}{l}\text { Number of } \\
\text { students }\end{array}$ & $\begin{array}{c}\text { Number of } \\
\text { teachers }\end{array}$ \\
\hline $1^{\text {st }}$ & $2^{\text {nd }}$ grade & 18 & 1 \\
\hline $2^{\text {nd }}$ & $2^{\text {nd }}$ grade & 16 & 1 \\
\hline $3^{\text {rd }}$ & $2^{\text {nd }}$ grade & 16 & 1 \\
\hline $4^{\text {th }}$ & $1^{\text {st }}$ grade & 16 & 2 \\
\hline $5^{\text {th }}$ & $1^{\text {st }}$ grade & 16 & 1 \\
\hline $6^{\text {th }}$ & $3^{\text {rd }}$ grade & 19 & 2 \\
\hline $7^{\text {th }}$ & $3^{\text {rd }}$ grade & 20 & 2 \\
\hline $8^{\text {th }}$ & $1^{\text {st }}$ grade & 15 & 2 \\
\hline Total & & 136 & 12 \\
\hline
\end{tabular}

The participants of the educational program were students 5 to 8 years old who came from the first, second and third grade of primary school. 3 of the 8 classes came from the private sector while the 5 classes came from public schools. The 12 teachers expressed their interest for the educational program and signed their classes by booking an open date to the Archaeological Museum of Ioannina, hence the sample was random.

Table 4. Research Data

\begin{tabular}{llll}
\hline \multicolumn{3}{c}{ Data collected } & \\
\hline Video recordings & $\begin{array}{l}\text { Students' } \\
\text { drawings/texts }\end{array}$ & Photographs & Field notes \\
\hline 12.73 hours & 136 & 39 & \\
\hline
\end{tabular}

The total data collected during the research was 12.73 hours of video recordings which were transcribed and analyzed, as well as, 136 student drawings/texts, 39 photographs and field notes which were also analyzed. The data analyzed in the present paper is related to the first implementation of the program and the $4^{\text {th }}$ phase of the expansive learning cycle, with the first class of second primary school students. The sample was 18 students. 


\subsection{Tool for Qualitative Data Analysis}

The tool used for the data analysis was NVivo 9 software which is produced by QSR International. It supports mixed research methods, but it is significantly helpful when dealing with great amount of data such as text, pictures, audio, video or other multimedia where a deep level of analysis is required. It is addressed mostly to researchers and it is applied in a wide range of different disciplines and research fields. It helps researchers organize and analyze qualitative data as wells as visualize them.

In the current paper, NVivo 9 software was used in coding, analyzing and visualizing data as well as finding relations and connect data with the CHAT framework. The collected data was organized into:

Sources where you can import and store the research materials into folders and sub-folders.

Nodes which are collections of references from the sources based on themes, cases or relationships and are created by coding sources into nodes.

Classifications which provide descriptive information about sources, nodes and relationships and are consisted of attributes.

Queries which constitute ways of gathering and exploring subsets of the data and are presented in the form of graphs to easily get a sense of what is happening in the data. NVivo offers different kind of queries, in this paper, word frequency, matrix coding, group queries are used.

Charts which display the visual representation of the data and are related to coding, sources and nodes.

\section{Results}

The preliminary results of the study so far have shown that the learning community plays an important role in science education. In the present case, the learning community is the museum with the collection room, "Dodoni", in which the educational program "Thunderbolt hunt" takes place, the instructor and secondarily the school since the audience is consisted of students and teachers. Therefore, the learning community in the data gatherd is connected judging by students' references and the educational program itself - with significant cultural tools which are consisted of museum's exhibits (Plakitsi, 2013) and the story used.

\section{Wind eagle eagle's aeolous listen winds this put find found finding \\ Why look exhbit exhibits we instructor you have doing cap some thunderbolt's thunderbolt boxes So lydia students can bottle bravo team teams panter say potost things hole sack materials leave photograph $\mathrm{goOd}$}

Figure 3. Word Frequency Query Tag Cloud from Students' Dialogues

In Figure 3, a word frequency query is extracted by NVivo in which the data was analyzed. It is a tag cloud which presents the most frequent words used in the students' dialogues during the implementation of the program. The size 
and the weight of the font indicates the frequency of the the words used by students. It is clear that thunderbolt is the most frequent word used. This is rather accountable since it is the main element of the educational program, it exists on every chosen exhibit, it is present in the story and it is the goal of the hunt. Apart from the thunderbolt we notice that the word "exhibit" is also frequently used as well as each of the program's exhibits separately, such as "eagle and panther". Main features of the story are also present in the tag cloud such as "wind, aeolus, sack". In general, the presence of the cultural tools in the learning community in students' dialogues is intense.

The same results are noticed in the word frequency query of the students' pictures (Figure 4.). Again, the word "thunderbolt" is the most frequent and again the cultural tools which are used in the learning community are present. We see the names of the exhibits, "eagle, panther, winged thunderbolt" as well as elements of the story, "wind, rain, house, clouds".

\section{ar eagle wind ${ }_{\text {lighthings }}$ rain ${ }_{\text {thumedotorls }}$ thunderbolts thunderbolt aroub balloon mane

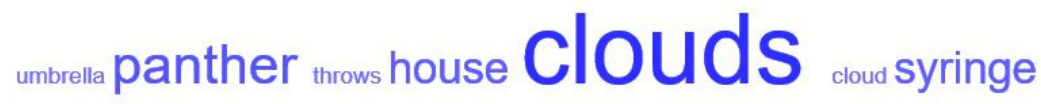 winged}

Figure 4. Word Frequency Query Tag Cloud from Students' Pictures

In the picture collection below (Picture 1) a sample of the students' pictures can be found. The first picture presents the exhibit of an eagle holding a thunderbolt. The next picture shows some elements of the story, the bad weather in the area of Dodoni's oracle with the clouds, the strong wind, the rain and the thunders. The last picture also shows an exhibit, the one with the winged thunderbolt.

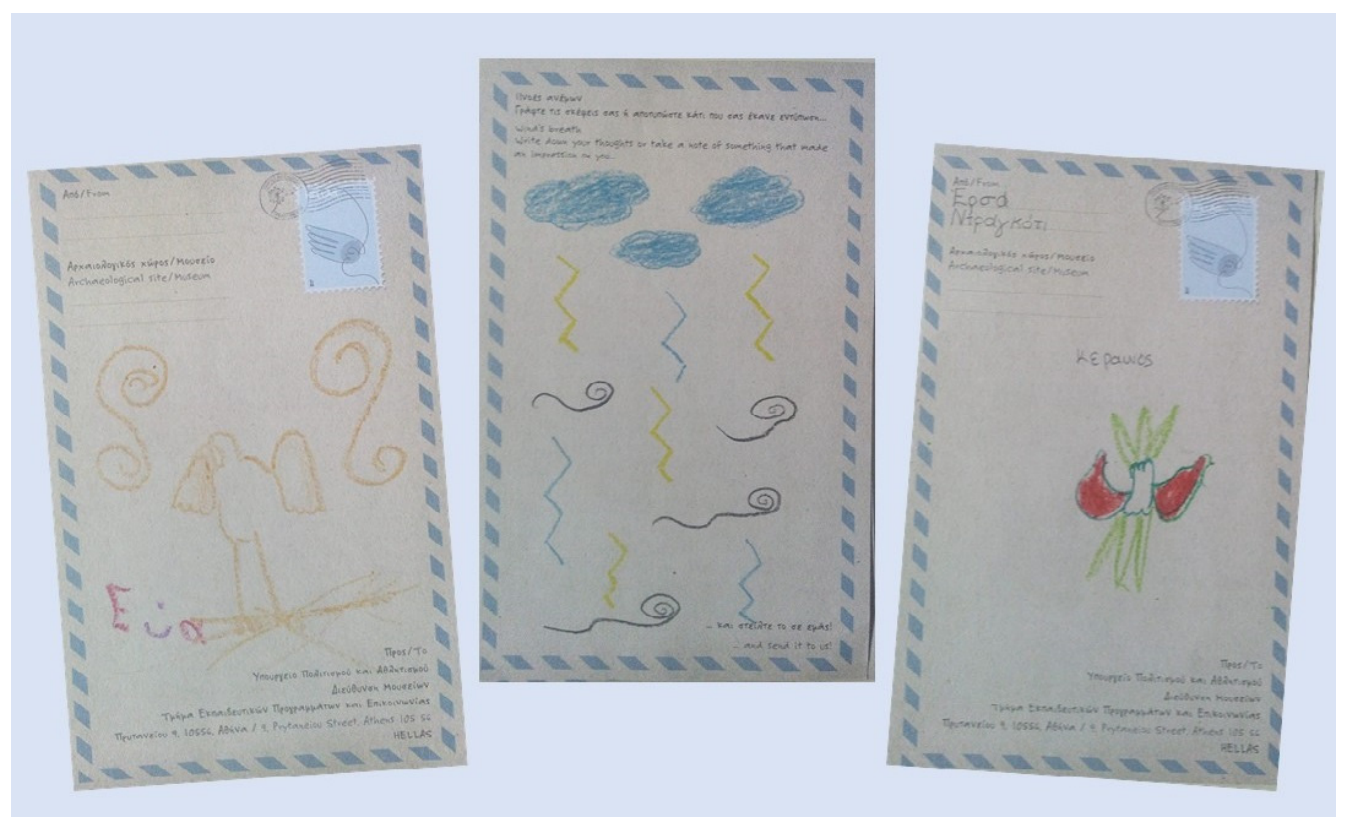

Picture 1. Students' Pictures Inspired by Exhibits and the Story 
Hence, just as in students' dialogues, so do their pictures represent the tools which are offered to students as cultural elements that mediate the goal of the educational program in the learning community. Representing the nodes of exhibits and story in relation with the different activities of the educational program in a matrix coding query (Figure 5) from NVivo, we remark that the one or the other appear in all the activities. So, the tools offered by the museum and used in the program appear in almost all the sources of data and indicate their presence during the educational program and thus, their importance in the process of experiencing and learning. The educational program "Thunderbolt hunt" aims to encourage students to practice scientific method skills through its activities within an alternative learning community.

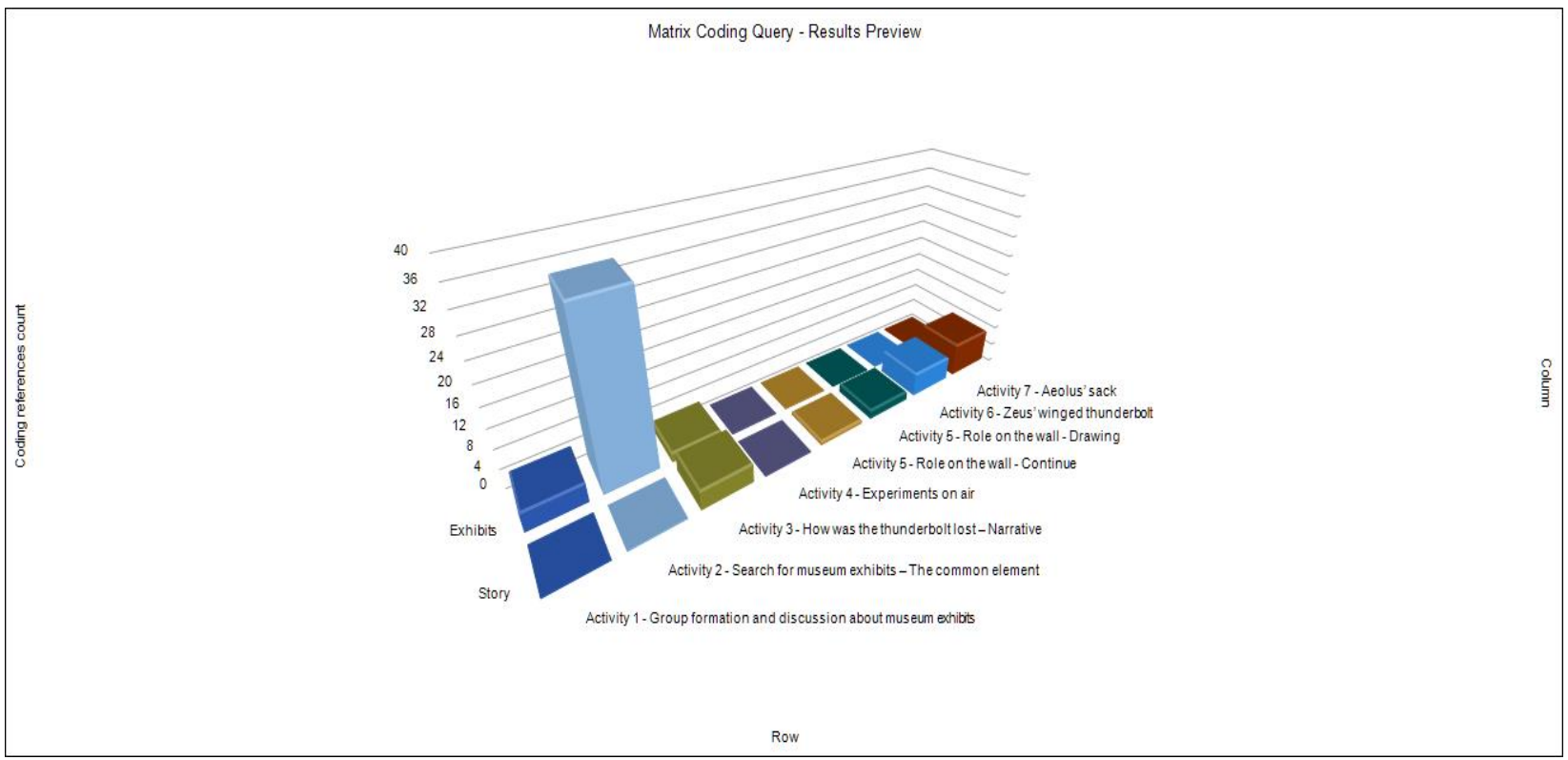

Figure 2. Matrix Coding Query of the Nodes Exhibits and Story in the Activities of the Educational Program

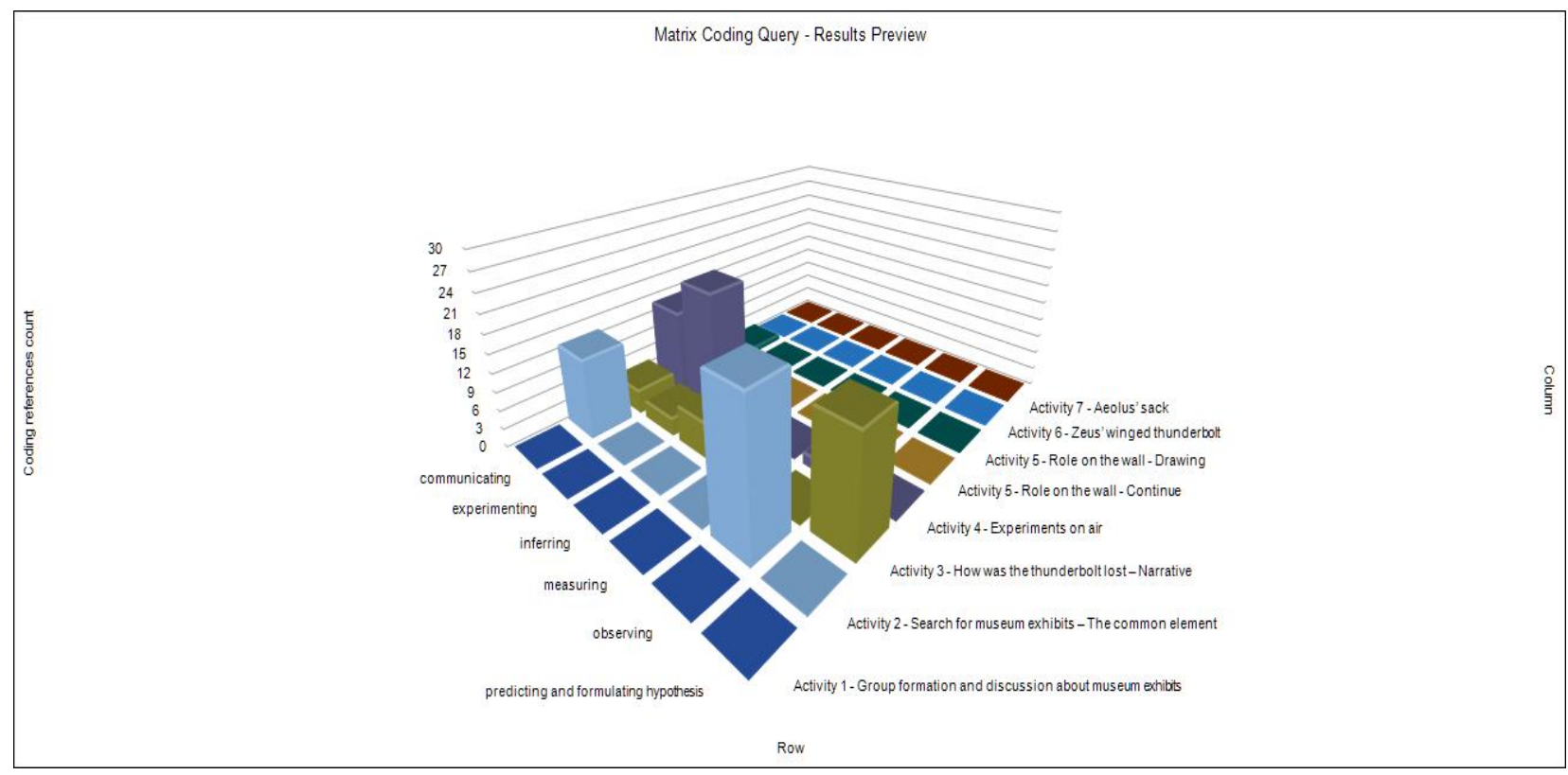

Figure 3. Matrix Coding Query of the Nodes Communicating, Experimenting, Inferring, Measuring, Observing, Predicting and Forming Hypothesis in the Activities of the Educational Program 
The scientific method skills appeared during the implementation of the program are presented in the matrix coding query above (Figure 6). The query represents the scientific method skills which were identified in students' dialogues in relation with the different activities of the program. Communicating, experimenting, inferring, measuring, observing, predicting and formulating hypothesis were the skills practiced by students during this implementation. The word frequency queries above (Figures $3 \& 4$ ) confirm this remark. The words "hole, bottle, materials, cap, boxes" in students' dialogues indicate the experiments with air and the words "balloon, syringe, air" in students' pictures also refer to the experiments.

It is noteworthy that in activities one, five, six and seven a scientific method skill doesn't seem to be utilized. The filed notes indicate that during these activities communication between students and instructor was high. Communication though, was not about scientific concepts and this explains why it is not represented in the graph. Students were using their language as a tool for cooperating, exchanging ideas and implementing the activities which is also very important in the development of students' articulation of the theoretical discourse.

In the group query below (Figure 7), the scientific method skills are represented in relation with the sources of data in which were identified. It is notable that scientific method skills and especially experimenting is also found in students' pictures. It shows that the process of experimenting in a museum was memorable for students who illustrated materials and experiments in their pictures.

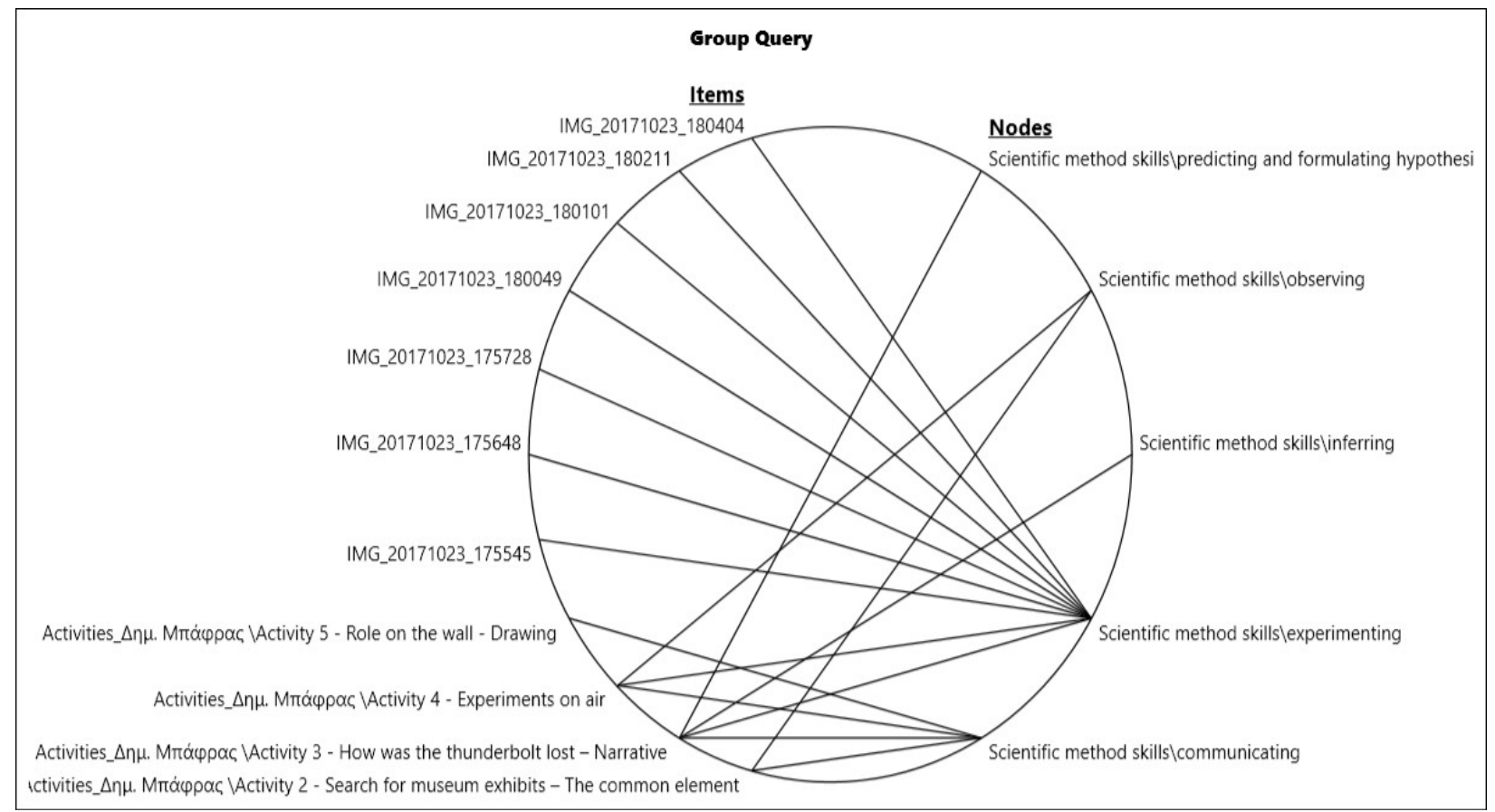

Figure 4. Group Query of the Nodes About the Scientific Method Skills in Relation to the Research Data

Some examples of those pictures can be found in the picture collection below (Picture 2). Lydia drew a girl syringe with the numbers on it and a balloon next to it. Another syringe is illustrated in the next picture where it is used as a pump to inflate a balloon. This was a students' idea of using the balloon and the syringe. It was tested when students had some time to see and peer into the materials they had in their disposal. They came to the conclusion that the syringe could not be used as a pump because when they pulled its piston to fill it up with air again, it just sucked all the air back from the balloon. The last picture illustrates a balloon which was one of the materials used in the experiments. 


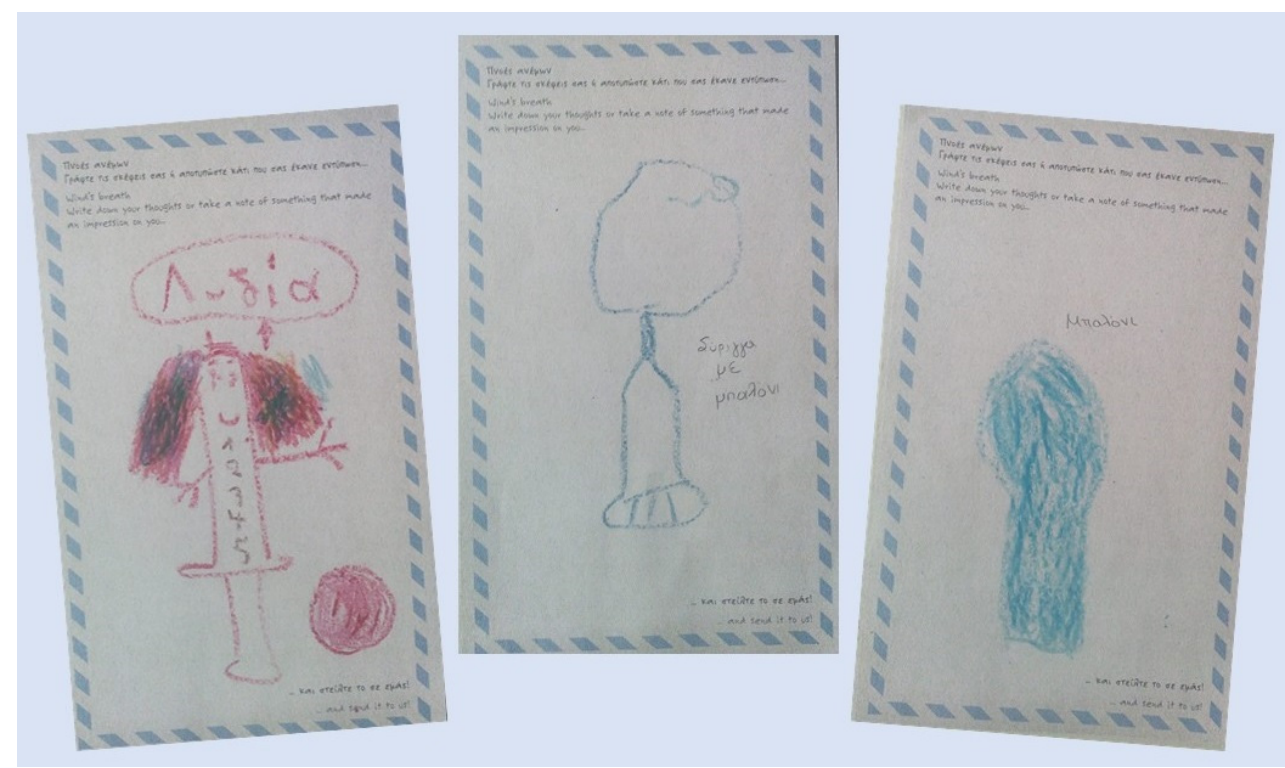

Picture 2. Students' Pictures Inspired by the Materials Used on the Experiments on Air

Both learning community and scientific method skills were identified in students' dialogues during the implementation of the program's activities. The latter entails interactions among the involved subjects within the learning community. These interactions were also studied and are presented in the tree map below (Figure 8). Most of the interactions are between the instructor and the students which is very reasonable since the instructor is the one who basically gives instructions. Students also seem to interact with the instructor while they give answers to questions and form their own questions. The teacher's presence was rather intense, but according to the field notes, it had ancillary character for the implementation of the activities. Very encouraging is the fact that despite the constraints with which the learning community is accompanied, interactions among the students and the teams are identified. This gives a piece of evidence that a museum of general interest as a learning community in spite of the rules it entails constitutes an appropriate field for hosting scientific educational programs.

Nodes compared by number of items coded

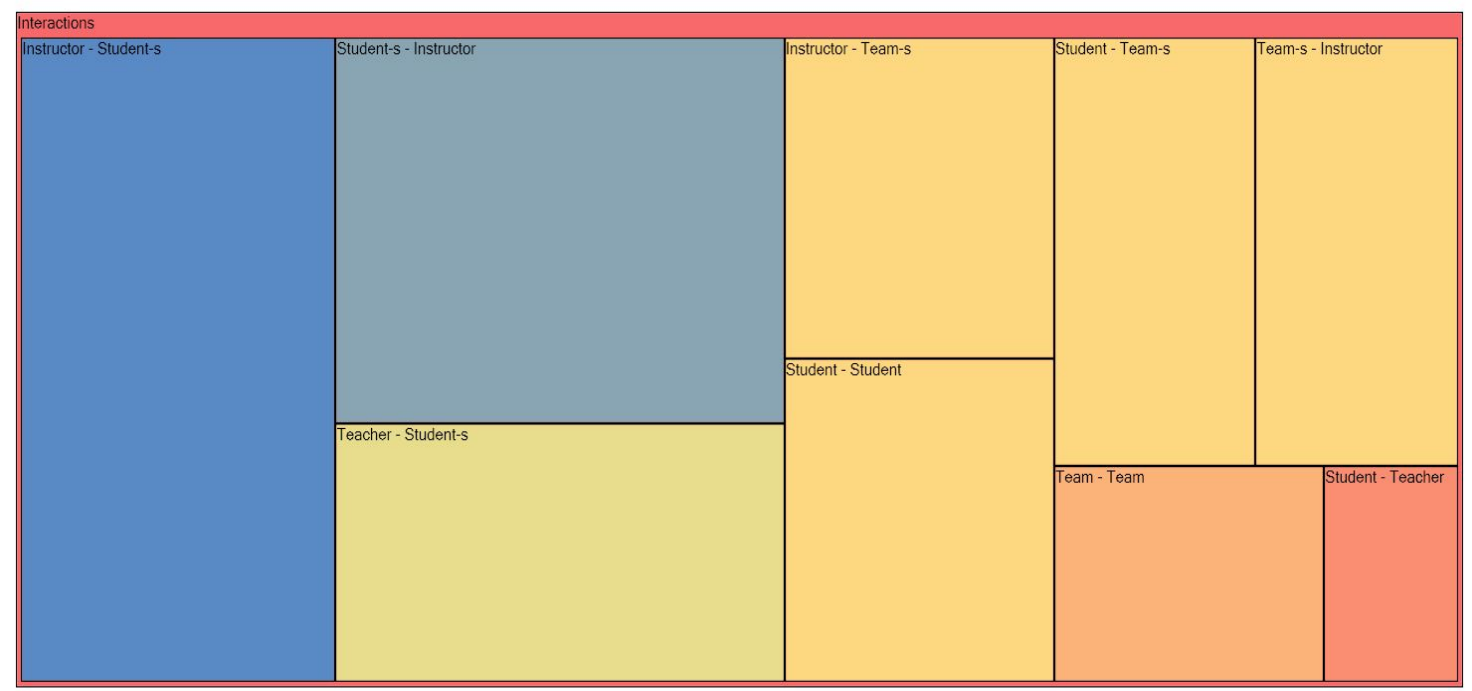

Figure 5. Tree Map of the Interactions Identified 
Of course, interactions are also studied under the prism of Activity Theory and as a structural element of the extended triangular model that Engestrom (1999) suggests (Figure 1). Interactions have a central role in Activity Theory because all the structural components of an Activity system are constantly interacting with each other. As a result, the object is achieved and moreover, the development of the Activity system is triggered. In the tree map below (Figure 9), the components of the extended triangular model of the Activity Theory are presented.

Nodes compared by number of items coded

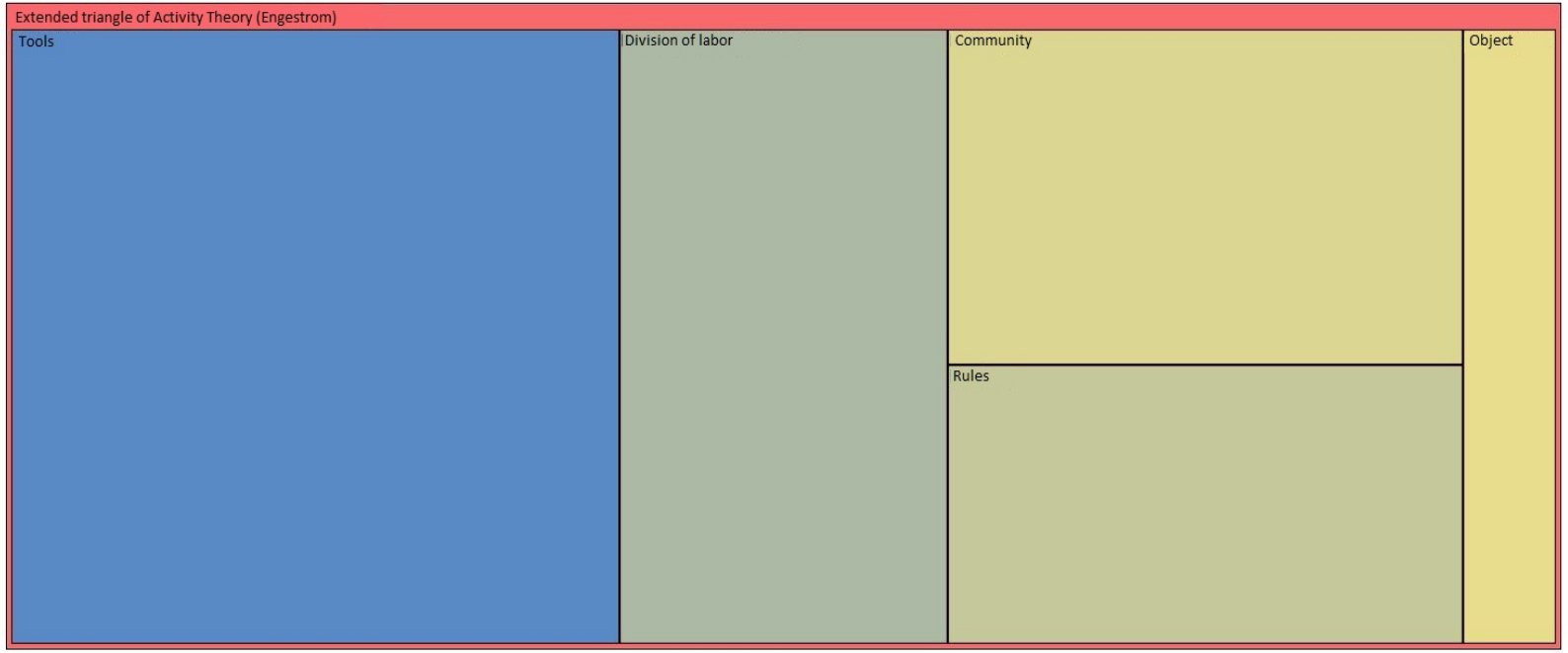

Figure 6. Tree Map of the Structural Components of the Activity System

The tree map (Figure 9) represents the structural components of the extended triangle in relation to the number of items coded. It is obvious that most of the references are related to the tools. This remark is very important because under the Activity Theory the use of tools mediate the object and students had a lot of different tools in their disposal in order to achieve the object. Division of labor is the next most frequent element. The instructor had the control of the program's flow. On the one hand the instructor had to overcome and balance the constraints of the learning community while on the other he had to observe students' involvement and glide the activities according to their interest. Therefore, students' involvement in the program's division of labor would imply a lot of risks considering the community's rules. What should be highlighted from the field notes is that among students and within the teams, the division of labor was undertaken by the students.

\section{Discussion}

The preliminary results of the research indicate that learning community influences learning process and science education. This is demonstrated by the strong appearance of the cultural tools offered to students within the learning community in the data. Students' references about the exhibits and the story are present during all the activities of the educational program (Figure 5). An Archaeological museum can be seen as an appropriate and attractive field of practicing scientific method skills when bridges between exhibits as part of the cultural heritage and science education are located. As described earlier, this research proposes an approach for students to interact with their social, cultural and historical environment. The design and implementation of scientific educational programs in cultural venues such as museums of general interest is proved an opportune field for further research.

The rules of the learning community are accompanied with constraints in the activities of the educational program in the museum. There are ways of dealing with these constraints so that educational programs such as "Thunderbolt hunt" can be implemented properly. In the case of the Archaeological museum of Ioannina, contradictions were identified regarding the use of tools and the rules. For example, in the Archaeological museum students can't touch the exhibits. Students' involvement though, in the process of experiencing is a key factor. This constraint was dealt in the case of the program "Thunderbolt hunt" with the introduction of tools beyond the learning community itself, by using external tools. In particular, tools for exhibit observation were given to the students in activity two and 
materials for the experiments were put into boxes and distributed to the teams in activity four. This way, a balance was attempted between students' free choice and guidance already from the design of the program. And that was based on the fact that during the activities, students had time to observe and use the tools not only in the way the program was pointing out but they could test the materials they had in their disposal and explore new ways of using them. Finally, in activity three, a story which explains where and how Zeus' thunderbolt was lost and the reason of the hunt was composed as a tool to encircle program's activities.

The availability of tools in students' hands is the key of the basic principle of CHAT, mediation. In "Thunderbolt hunt", students mediated the experience of air and its properties through practicing scientific method skills by using tools. This is clear in activities two, three and four where external tools are given to students while higher levels of practicing scientific method skills are concurrently located in the same activities (Figure 6).

Within the learning community of the museum, the division of labor is undertaken almost entirely by the instructor. This is unfortunately unavoidable in a community with strict rules such as in archaeological museums. There was a struggle, right from the start to lighten the instructor's authority and it was really difficult to find ways to make him more flexible when the timetable and rules were not. The instructor has great responsibility when implementing an educational program. The proper time management is an essential skill for an instructor. The instructor observes students' interest in every activity giving them the required time or moving to the next activity when students' interest is lost, or students have completed the activity. Finally, it is useful for the instructor to recognize when to intervene in the work of the teams, to support them and help them go further (scaffolding) as well as when to let the teams evolve and achieve the goal independently (fading). It seems that in the implementation of "Thunderbolt hunt", the instructor along with his authority, didn't restrict the interactions between the subjects. Judging from the data analysis, the level of interactions was high not only from the instructor's side but also from the side of the students, the teams and between them (Figure 8).

All the above constitute principles of the framework for the design and implementation of educational programs inspired by museum artifacts, derived by scientific concepts of school science education curriculum and implemented in informal settings, which is introduced by the present study.

Summing up, CHAT can function as a channel of scientific knowledge diffusion through the cultivation of scientific method skills and their connection to aspects of students' everyday life as well as their culture. Learning community constitutes a dynamic meeting place of students with their social, cultural and historical backgrounds. Museums can function, through their educational programs, not just as simple transponder but as a mediator of scientific knowledge.

\section{Acknowledgement}

This research was supported by the Hellenic Scholarship Foundation (IKY), under the Operational Program "Human Resources Development, Education and Lifelong Learning" (NSRF 2014-2020) with Priority Axes 6,8,9, co-financed by the European Social Fund (ESF) and the Greek government.

\section{References}

Basharina, O. K. (2007). An Activity theory perspective in on student-reported contradictions in international telecollaboration. Language Learning and Technology, 11(2), 82-103.

Beetlestone, J. G., Johnson, C. H., Quin, M., \& White, H. (1998). The Science Center Movement: contexts, practice, next challenges. Public Understanding of Science, 7(1), 5-26. https://doi.org/10.1177/096366259800700101

Cole, M. (1988). Cross-Cultural Research in the Sociohistorical Tradition. Human Development, 31, 137-157. https://doi.org/10.1159/000275803

Cole, M. (1998). Cultural Psychology: A Once and Future Discipline. Cambridge, MA: Harvard University Press.

Engeström, Y. (1987). Learning by expanding: An activity-theoretical approach to developmental research. Helsinki: Orienta-Konsultit.

Engeström, Y. (1993). Developmental studies of work as a test bench of activity theory. In S. Chaiklin and J. Lave (Eds.), Understanding practice: perspectives on activity and context. Cambridge: Cambridge University Press, 64-103. https://doi.org/10.1017/CBO9780511625510.004

Engeström, Y. (1999). Activity theory and individual and social transformation. In Y. Engeström, R. Miettinen \& R-L. Punamääki (Eds.), Perspectives on Activity Theory. Cambridge: Cambridge University Press. 
Engeström, Y. (2003). The horizontal dimension of expansive learning: Weaving a texture of cognitive trails in the terrain of health care in Helsinki. In Paper presented at the international symposium "New Challenges to Research on Learning", March 21-23. University of Helsinki, Finland.

Fleer, M. (2009). The cultural construction of child development: Creating institutional and cultural intersubjectivity. International Journal of Early Years Education, 14(2), 127-140. https://doi.org/10.1080/09669760600661294

Foot, K., \& Groleau, C. (2011). Contradictions, transitions, and materiality in organizing processes: An activity theory perspective. First Monday, 16(6), 1-21. https://doi.org/10.5210/fm.v16i6.3479

Foot, K. (2014). Cultural-historical activity theory: Exploring a theory to inform practice and research. Journal of Human Behavior in Social Environments, 12(3), 329-347. https://doi.org/10.1080/10911359.2013.831011

Gutwill, J. P., \& Allen, S. (2012). Deepening Students' Scientific Inquiry Skills During a Science Museum Field Trip. Journal of the Learning Sciences, 21(1), 130-181. https://doi.org/10.1080/10508406.2011.555938

Holzman, L. (2010). Without creating ZPDs there is no creativity. In M. C. Connery et al. (Eds), Vygotsky and Creativity: A cultural-historical approach to play, meaning making and the arts. New York, NY: Peter Lang (27-39).

John-Steiner, V., Connery, M.C., \& Marjanovic-Shane, A. (2010). Dancing with the muses: A cultural-historical approach to play, meaning making and creativity. In M. C. Connery et al. (Eds), Vygotsky and Creativity: A cultural-historical approach to play, meaning making and the arts. New York, NY: Peter Lang (3-15).

Kaptelinin, V., \& Nardi, B. (2006). Acting with technology: Activity theory and interaction design. Cambridge: MIT Press.

Koliopoulos, D. (2005). The Didactic approach of a science museum. Athens: Metexmio [in Greek]

Kolokouri, E., \& Plakitsi, K. (2016). A CHAT Approach of Light and Colors in Science Teaching for the Early Grades. World Journal of Education, 6(4), 1-13. https://doi.org/10.5430/wje.v6n4p1

Kolokouri, E., Theodoraki X., \& Plakitsi, K. (2012). A Cultural Historical Activity Theory Approach In Natural Sciences Education Laboratory Lessons Towards Reforming Teachers Training. World Journal of Education, 2(2), 23-40. https://doi.org/10.5430/wje.v2n2p23

Kornelaki, A. C., \& Plakitsi, K. (2018). Identifying Contradictions in Science Education Activity Using the Change Laboratory Methodology. World Journal of Education, 8(2), 27-45. https://doi.org/10.5430/wje.v8n2p27

Kuutti, K. (1996). Activity Theory as a potential framework for human computer interaction research. In B. Nardi (Ed.). Context and consciousness: Activity Theory and human computer interaction. Cambridge, MA: MIT Press (17-44).

Leont'ev, A. N. (2009). The development of mind. Pacifica USA: Marxists Internet Archive.

Nanni, E., \& Plakitsi, K. (2013). Investigating New Paths in the Teaching of Plant Processes in Elementary Schools. World Journal of Education, 3(4), 52-70. https://doi.org/10.5430/wje.v3n4p52

Plakitsi, K. (2013). Activity Theory in Formal and Informal Science Education. The Netherlands: Sense Publishers. https://doi.org/10.1007/978-94-6091-317-4

Plakitsi, K. (2008). Didactics of Natural Sciences in Pre-School and Early School Age: Modern Trends and Perspectives. Athens: Patakis [in Greek]

Roth, W.-M. (2011). Science in/for early childhood: More than lip service. In K. Plakitsi (Ed.), Sociocultural and Sociocognitive Approaches in the Didactics of Natural Sciences in Early Childhood. Athens: Patakis.

Roth, W.M., Goulart, M.I.M., \& Plakitsi, K. (2013). Science Education during Early Childhood. A Cultural Historical Perspective. Dordtrecht: Springer. https://doi.org/10.1007/978-94-007-5186-6

SCWS. (2017). Tokyo protocol. Retrieved May 15, 2018 from https://scws2017.org/tokyo_protocol/

Stamoulis, E., \& Plakitsi, K. (2014). The CHAT as a methodological tool in research on science teaching in primary education, Science Education. Research and Praxis, 2014(50-51), 60-84.

Stetsenko, A. (2017). The Transformative Mind. Expanding Vygotsky's Approach to Development and Education. New York, NY: Cambridge University Press. https://doi.org/10.1017/9780511843044

Stylianou, L., \& Plakitsi, K. (2015). A Cultural Historical Activity Theory Approach to an Informal Environmental Education Programme about a Local River, Science Education. Research and Praxis, 2015(52-53), 45-61. 
Tu, Y. (2006). Preschool science environment: What is available in a preschool classroom? Early Childhood Education Journal, 33, 245-251. https://doi.org/10.1007/s10643-005-0049-8

United Nations. (2015). Sustainable Development Goals. Retrieved May 15, 2018, from http://www.undp.org/content/undp/en/home/sustainable-development-goals.html

Virkkunen, J., \& Newnham, D.S. (2013). The Change Laboratory: A tool for collaborative development of work and education. Rotterdam: Sense Publishers. https://doi.org/10.1007/978-94-6209-326-3

Vygotksy, L.S. (1978). Mind in society: The development of higher psychological processes. In M. Cole et al. (Eds.), Cambridge: Harvard University Press.

Wellington, J. (1998). Formal and informal learning in science: The role of the interactive science centers. Physics Education, 25, 247-257. https://doi.org/10.1088/0031-9120/25/5/307

Wertsch, J. (1998). Mind as action. New York, NY: Oxford University Press. 